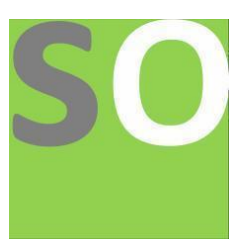

Article title: Generation of Fractals using Polar Coordinates

Authors: Serguei Charonov[1]

Affiliations: Horiba France SAS, 455 Avenue Eugène Avinée, 59120 Loos, France[1]

Orcid ids: 0000-0002-6281-0514[1]

Contact e-mail: serguei.charonov@horiba.com

License information: This work has been published open access under Creative Commons Attribution License http://creativecommons.org/licenses/by/4.0/, which permits unrestricted use, distribution, and reproduction in any medium, provided the original work is properly cited. Conditions, terms of use and publishing policy can be found at https://www.scienceopen.com/.

Preprint statement: This article is a preprint and has not been peer-reviewed, under consideration and submitted to ScienceOpen Preprints for open peer review.

Links to data: https://doi.org/10.6084/m9.figshare.16608541

DOI: 10.14293/S2199-1006.1.SOR-.PPBKDMO.v1

Preprint first posted online: 13 September 2021

Keywords: Fractals, Julia set, Mandelbrot set 


\title{
Generation of Fractals using Polar Coordinates
}

\author{
S. Charonov, Horiba France SAS, 455 Avenue Eugène Avinée, 59120 Loos, France \\ E-mail : serguei.charonov@horiba.com
}

\begin{abstract}
.
The article describes an algorithm for generating fractals using polar coordinates. The classic Julia and Mandelbrot polynomial iteration applied to a complex number is replaced by an iteration with separate functions for distance and angle. A polynomial function is used for an angle and a power function for a distance. Varying the functions parameters allows to create a wide range of attractive pictures. Distance values are used for coloring fractal images.
\end{abstract}

\section{Keywords.}

Fractals, Julia set, Mandelbrot set.

\section{Introduction.}

Beginning with the classical studies of Benoit Mandelbrot (1), who expanded on the work of Gaston Julia (2), many researchers have studied Julia sets and Mandelbrot sets from different sides (3-8). Various generalizations of these sets have been proposed. Many iteration processes (such as Ishikawa, Noor, SP, MM iterations) have been successfully used to generate fractals.

In this article, the classic iteration $\mathrm{z} \rightarrow \mathrm{z}^{2}+\mathrm{c}$ has been replaced, using polar coordinates, by iterating with separate functions for distance and angle. A partial escape criterion for iteration is proposed along with a graphical presentation of the result sets.

\section{Algorithms and Results.}

The Mandelbrot set $\mathrm{M}$ for the function $\mathrm{Q}_{\mathrm{c}}(\mathrm{z})$ can be defined in the following way (4):

$$
\mathrm{M}=\left\{\mathrm{c} \in \mathrm{C}:\left\{\mathrm{Q}_{\mathrm{c}}^{\mathrm{n}}(0)\right\} \text { does not tend to } \infty \text { as } \mathrm{n} \rightarrow \infty\right\},
$$

For classical Mandelbrot set $\mathrm{Q}_{\mathrm{c}}(\mathrm{z})=\mathrm{z}^{2}+\mathrm{c}$.

The proposed iteration scheme uses the polar representation of the complex number $z=r e^{i \varphi}$. $\mathrm{Q}_{\mathrm{c}}(\mathrm{z})$ can be defined as

$$
\mathrm{Q}_{\mathrm{c}}(\mathrm{z})=\mathrm{T}(\mathrm{r}, \varphi)+\mathrm{c}
$$

where 


$$
\mathrm{T}(\mathrm{r}, \varphi)=\mathrm{r}^{\mathrm{s}(\mathrm{r})} \mathrm{e}^{\mathrm{ip}(\varphi)}
$$

and $\mathrm{s}$ and $\mathrm{p}$ are polynomials. For this work, $\mathrm{s}$ is a constant function $\mathrm{s}(\mathrm{r})=\mathrm{D}$, and $\mathrm{p}$ is a polynomial of order $2 \mathrm{p}(\varphi)=\mathrm{A} \varphi^{2}+\mathrm{B} \varphi+\mathrm{C}$. To obtain the classical Mandelbrot set, the values of the parameters should be $\mathrm{A}=\mathrm{C}=0$ and $\mathrm{B}=\mathrm{D}=2$.

The escape criterion can be obtained as follows: if there exists $\mathrm{k} \geq 0$ such that for the sequence $\mathrm{Z}_{\mathrm{k}}, \mathrm{Z}_{\mathrm{k}+1}, \ldots$

$$
\left|z_{n}\right|<\left|z_{n+1}\right|
$$

and the sequence is not limited, then $\left.\mathrm{Q}_{\mathrm{c}}^{\mathrm{n}} \mathrm{z}\right) \rightarrow \infty$ as $\mathrm{n} \rightarrow \infty$.

$$
\left|z_{n}\right|=r_{n}<\left|z_{n+1}\right|=r_{n+1}=\left|T\left(r_{n}, \varphi_{n}\right)+c\right|
$$

If $r_{n}{ }^{D} \geq|c|$ then

$$
\mathrm{r}_{\mathrm{n}}<\mathrm{r}_{\mathrm{n}}{ }^{\mathrm{D}}-|\mathrm{c}| \leq\left|\mathrm{T}\left(\mathrm{r}_{\mathrm{n}}, \varphi_{\mathrm{n}}\right)+\mathrm{c}\right|
$$

and in the condition $\mathrm{D}>1$, the value of the escape threshold $\mathrm{r}$ can be calculated as a solution to the equation

$$
\mathrm{r}^{\mathrm{D}}-\mathrm{r}>|\mathrm{c}|
$$

Taking into account that the sequence $\left|z_{k}\right|,\left|z_{k+1}\right|, \ldots$ is bounded by sequence $u_{n}=\left|z_{n}\right|, u_{n+1}, \ldots,\left|z_{n}\right|$ $\geq u_{n}$, where

$$
\mathrm{u}_{\mathrm{n}+1}=\mathrm{u}_{\mathrm{n}}^{\mathrm{D}}-|\mathrm{c}|
$$

and that

$$
\mathrm{u}_{\mathrm{n}+2}-\mathrm{u}_{\mathrm{n}+1} \geq \mathrm{u}_{\mathrm{n}+1}-\mathrm{u}_{\mathrm{n}}>0
$$

then $\left.\mathrm{Q}_{\mathrm{c}}^{\mathrm{n}} \mathrm{z}\right) \rightarrow \infty$ as $\mathrm{n} \rightarrow \infty$.

Figures 1 shows the escape threshold for some D values. Figure 2 gives the examples of escaped and bounded tracks. The fractals used for tracks generation are presented in Figures 3-6. To create a color picture the distance $|z|$ value is mapped in the palette lookup table. 


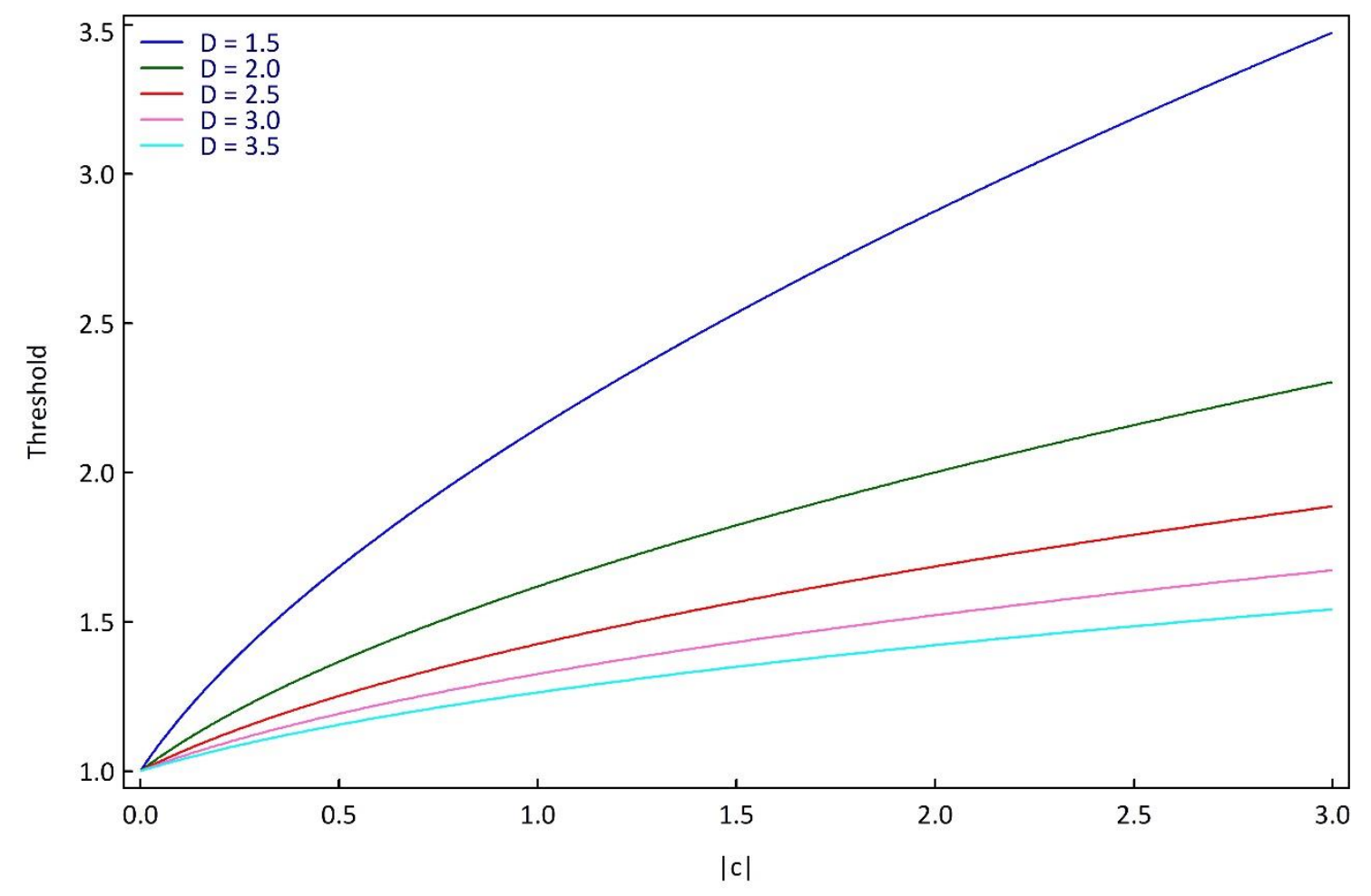

Fig 1. The escape threshold as function $|c|$ for different D parameters.

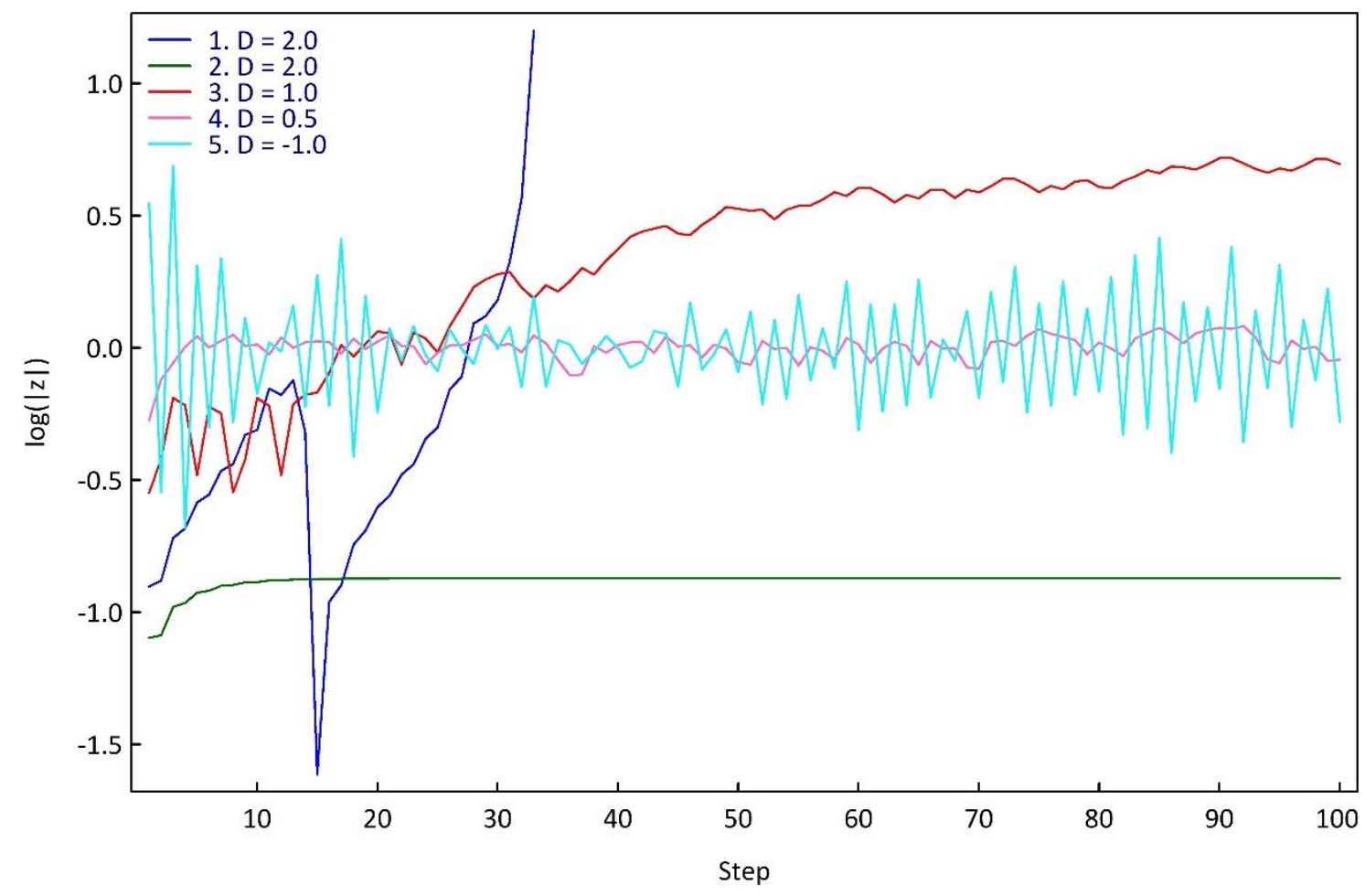

Fig 2. Logarithm of distance as function of the step number. The graph 1 is an escaped track for $\mathrm{c}=(0.25,0.25)$, other tracks are generated with $\mathrm{c}=(0.2,0.2)$. The track 3 is rather escaped, and tracks 2,4,5 are bounded. A negative value of D results in a "vibration" effect. Fractals are shown in Figures 3-6. 


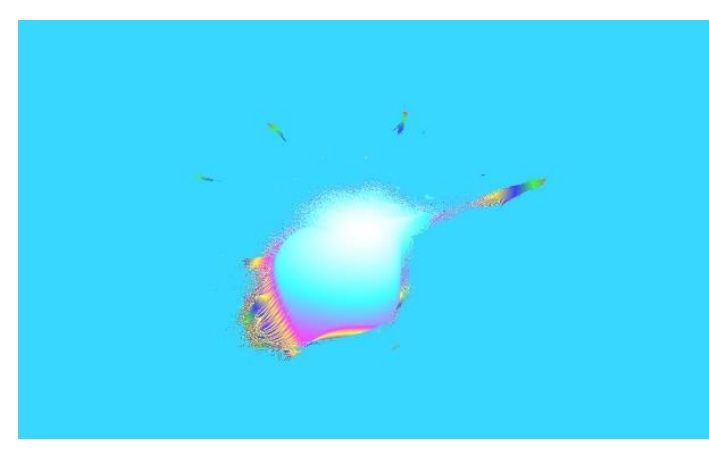

Figure 3. Fractal "Bird". A=1.3, $\mathrm{B}=3.45, \mathrm{C}=45.0, \mathrm{D}=2.0$.

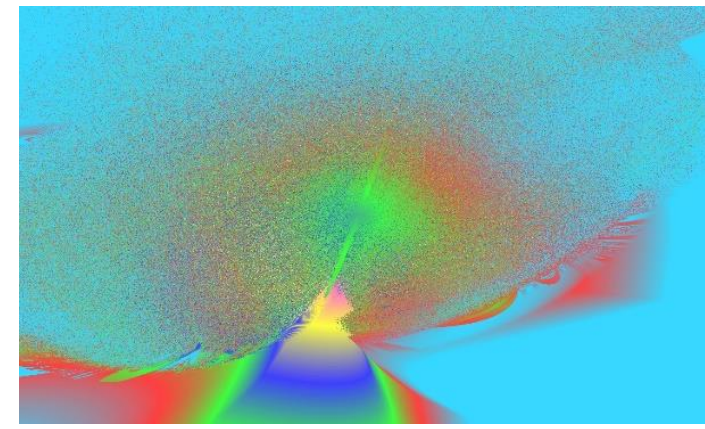

Figure 5. Fractal "Bird", D = 0.5.

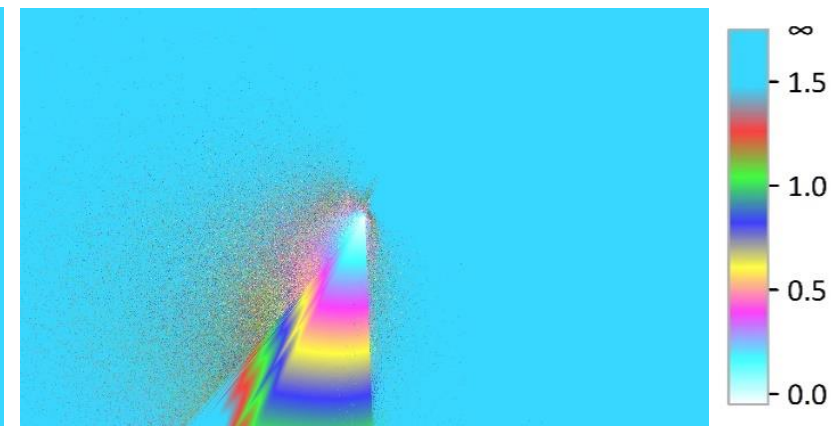

Figure 4. Fractal "Bird", D = 1.0.

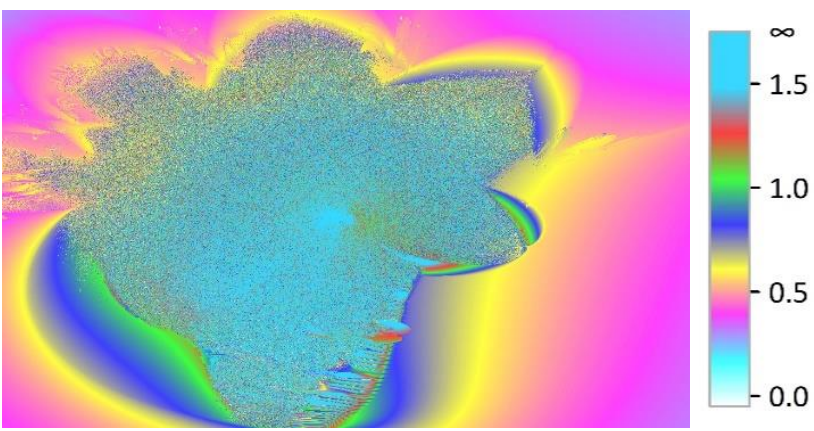

Figure 6. Fractal "Bird", D = -1.0.

By changing parameters A, B, C, D, many attractive images can be obtained. Figures 7-22 show some of them. Depending on the values of the parameters, 2 types of fractals can be identified. "Solid" fractals usually with D > 1, similar to the Mandelbrot set, and "dust" fractals usually with $|\mathrm{D}|<1$. Features of both classes present mainly in every fractal.

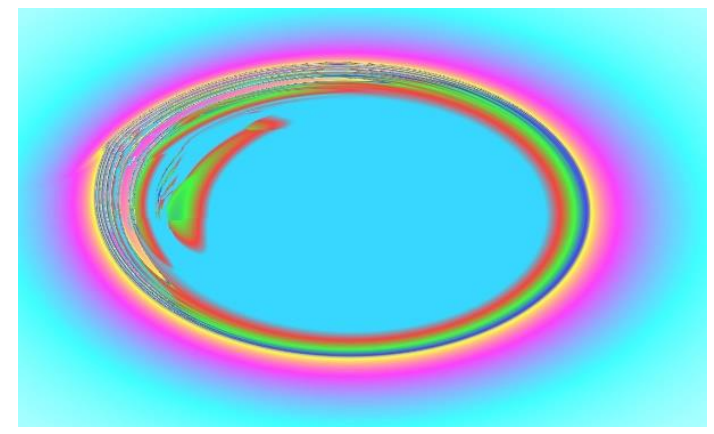

Figure 7. Fractal "Ring". $\mathrm{A}=-0.06$, $\mathrm{B}=1.01, \mathrm{C}=-1.39, \mathrm{D}=-2.37$.

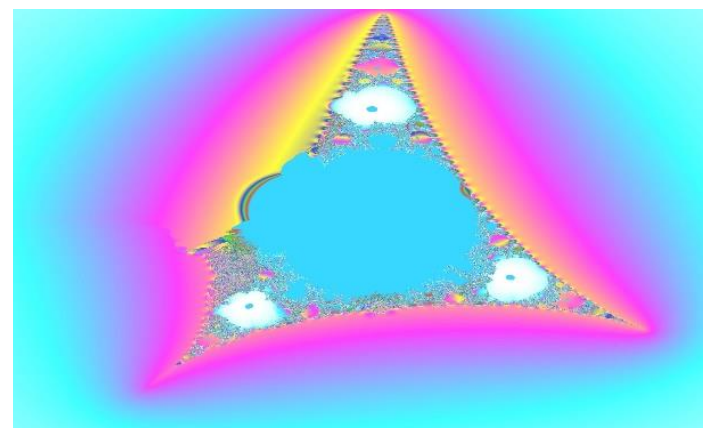

Figure 8. Fractal "Triangle". $\mathrm{A}=-0.21$, $\mathrm{B}=-2.24, \mathrm{C}=-1.23, \mathrm{D}=-2.09$. 


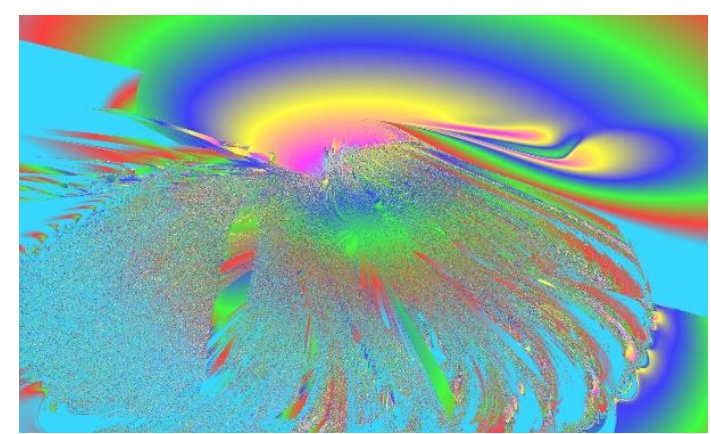

Figure 9. Fractal "Splitting". $A=0.27$, $\mathrm{B}=1.35, \mathrm{C}=2.95, \mathrm{D}=0.61$.

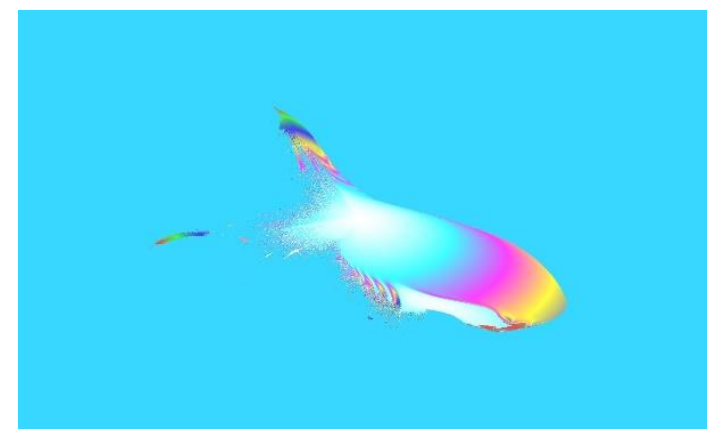

Figure 11. Fractal "Shark". $A=0.87$, $\mathrm{B}=0.15, \mathrm{C}=-2.04, \mathrm{D}=1.71$.

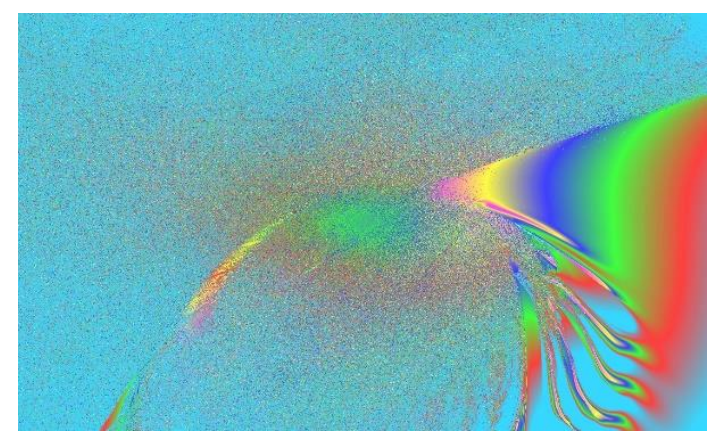

Figure 13. Fractal "River Delta", $\mathrm{A}=1.01, \mathrm{~B}=-0.65, \mathrm{C}=2.05, \mathrm{D}=0.61$.

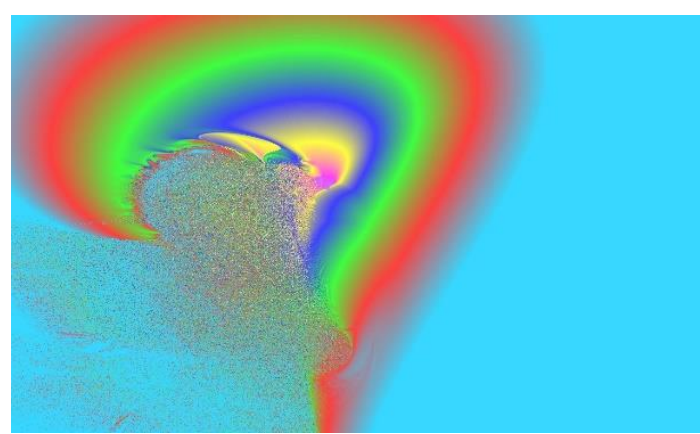

Figure 10. Fractal "Question mark". $A=-0.65$, $\mathrm{B}=-0.63, \mathrm{C}=0.66, \mathrm{D}=0.52$.

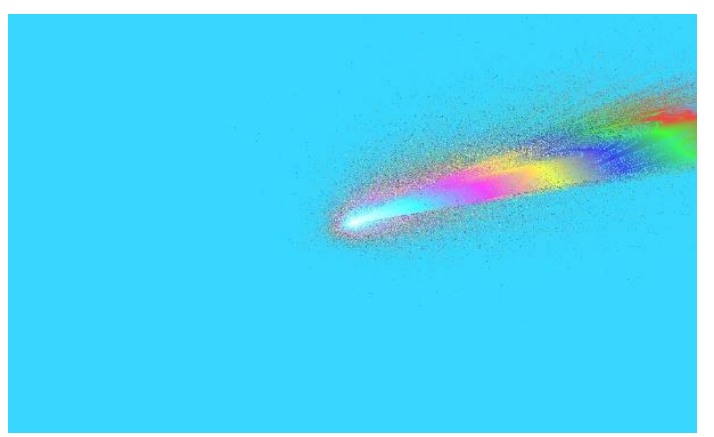

Figure 12. Fractal "Comet". $\mathrm{A}=-2.15, \mathrm{~B}=-$ 2.99, $\mathrm{C}=2.19, \mathrm{D}=1.04$.

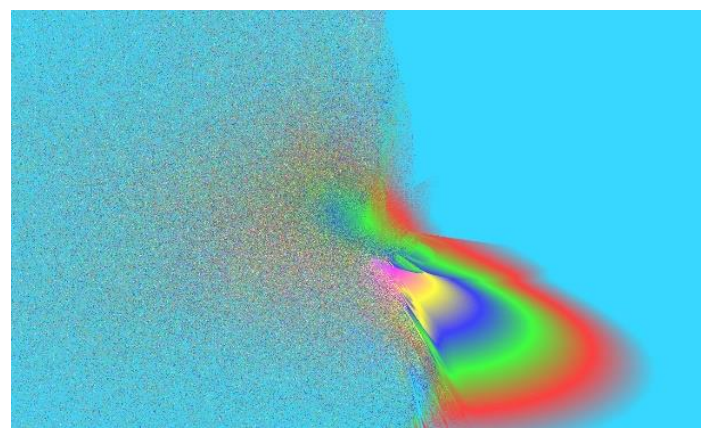

Figure 14. Fractal "Dichotomy", $A=1.55$, $\mathrm{B}=0.20, \mathrm{C}=-1.45, \mathrm{D}=0.67$. 

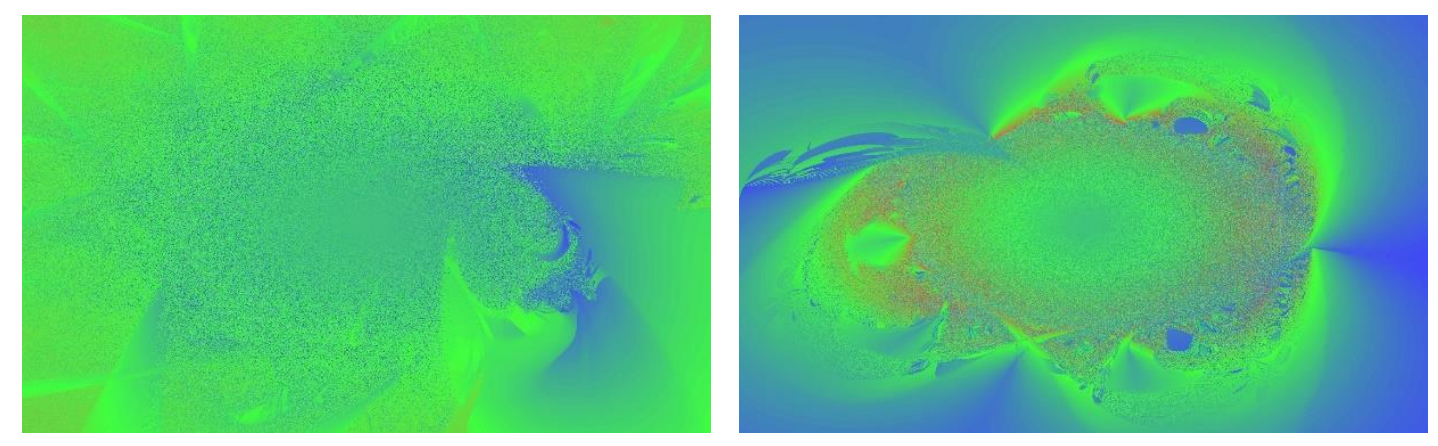

Figure 15. Fractal "Green Rays", $\mathrm{A}=2.50, \mathrm{~B}=-2.40, \mathrm{C}=2.88, \mathrm{D}=0.10$.

Figure 16. Fractal "Green Bee". $A=0.11$, $\mathrm{B}=2.61, \mathrm{C}=-0.28, \mathrm{D}=-0.14$.
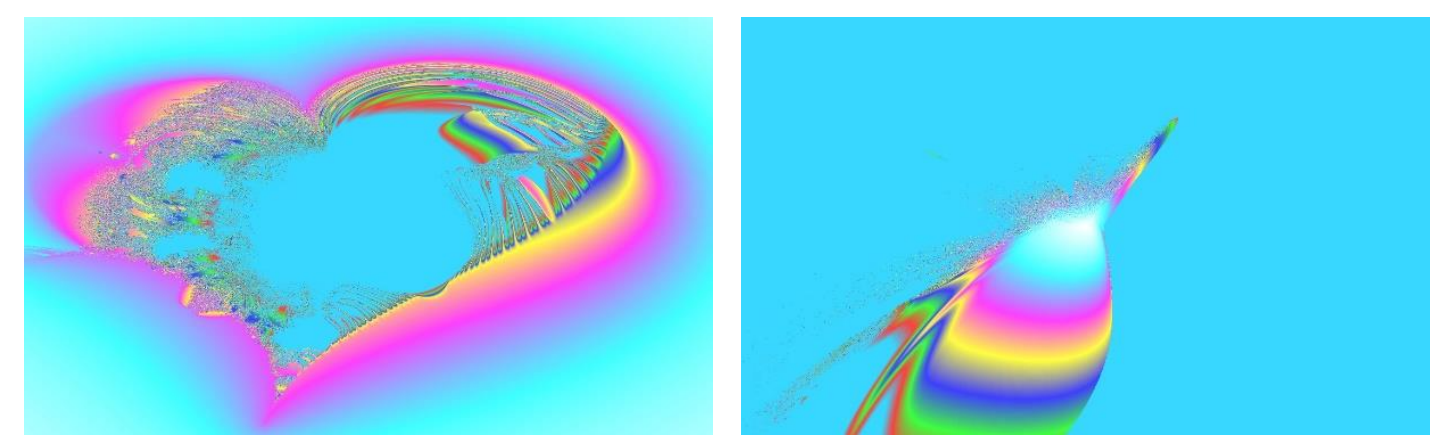

Figure 17. Fractal "Heart". $A=-1.00$, $\mathrm{B}=0.16, \mathrm{C}=1.97, \mathrm{D}=-2.31$.

Figure 18. Fractal "Bird 2". $\mathrm{A}=0.60, \mathrm{~B}=-$ $1.40, \mathrm{C}=-0.19, \mathrm{D}=1.26$.

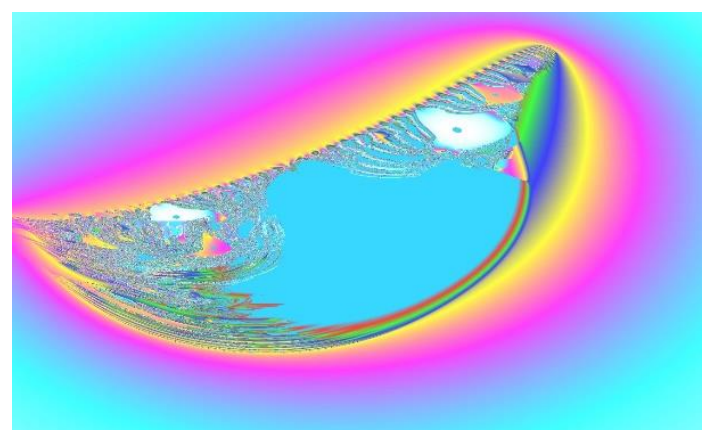

Figure 19. Fractal "Nose" $\mathrm{A}=0.92$, $\mathrm{B}=0.09, \mathrm{C}=-0.90, \mathrm{D}=0.81$.

Figure 20. Fractal "Imaginary Banana". $\mathrm{A}=0.44, \mathrm{~B}=-0.16, \mathrm{C}=1.57, \mathrm{D}=-1.85$. 


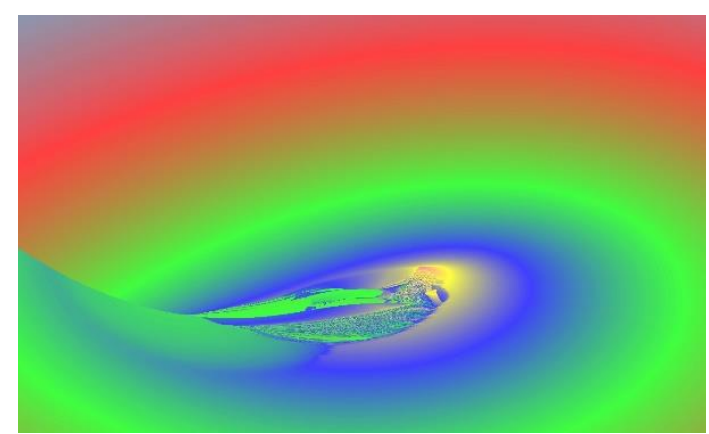

Figure 21. Fractal "Source of Energy". $\mathrm{A}=0.18, \mathrm{~B}=0.32, \mathrm{C}=-2.01, \mathrm{D}=0.25$.

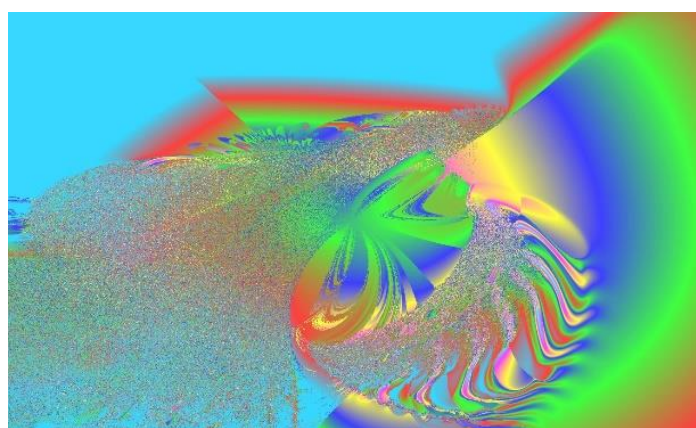

Figure 22. Fractal "Time Spiral" $\mathrm{A}=0.58$, $\mathrm{B}=0.39, \mathrm{C}=2.24, \mathrm{D}=0.51$.

\section{Conclusions.}

The proposed method allows to create attractive-looking fractals. An escape criterion is proposed for a certain range of parameters. The algorithm is simple to implement, it can be adapted and extended.

\section{Supplemental Material}

The datasets can be downloaded from (9). The online version of the fractal generator is available at (10).

\section{References.}

[1] M. Barnsley, Fractals Everywhere, 2nd ed. Boston, MA, USA: Academic,1993.

[2] B. B. Mandelbrot, The Fractal Geometry of Nature, vol. 2. New York, NY, USA: WH Freeman, 1982

[3] M. Tanveer, I. Ahmed, A. Raza, S. Nawaz, Y-P. Lv. New escape conditions with general complex polynomial for fractals via new fixed point iteration[J]. AIMS Mathematics, 2021, 6(6): 5563-5580. doi:10.3934/math.2021329

[4] Y. C. Kwun, M. Tanveer, W. Nazeer, K. Gdawiec and S. M. Kang, "Mandelbrot and Julia Sets via Jungck-CR Iteration With \$s\$ -Convexity," in IEEE Access, vol. 7, pp. 12167-12176, 2019, doi: 10.1109/ACCESS.2019.2892013.

[5] H. Qi, M. Tanveer, M. S. Saleem and Y. Chu, "Anti Mandelbrot Sets via Jungck-M Iteration," in IEEE Access, vol. 8, pp. 194663-194675, 2020, doi: 10.1109/ACCESS.2020.3033733.

[6] M. Kumari, S. Kumari, R. Chugh. Generation of Anti-Fractals in SP-Orbit. International Journal of Computer Trends and Technology. 43. 105-112, 2017, doi: 10.14445/22312803/IJCTT-V43P115. 
[7] A. Y. Cherny, E. M. Anitas, A. I. Kuklin, M. Balasoiu and V. A. Osipov. Scattering from generalized Cantor fractals. J. Appl. Cryst. (2010). 43, 790-797, doi:10.1107/S0021889810014184

[8]. B. Martin. Inherent Generation of Fractals by Cellular Automata. Complex Systems 8 (1994) 347-366.

[9]. Data sets. https://doi.org/10.6084/m9.figshare.16608541

[10]. The online fractal generator.

https://spectralmultiplatform.blogspot.com/p/polar-fractals.html 